\title{
Radiolucency below the crown of mandibular horizontal incompletely impacted third molars and acute inflammation in men with diabetes
}

This article was published in the following Dove Press journal:

Clinical, Cosmetic and Investigational Dentistry

8 May 2009

Number of times this article has been viewed

\section{Minoru Yamaoka \\ Yusuke Ono \\ Masahide Ishizuka \\ Kouichi Yasuda \\ Takashi Uematsu \\ Kiyofumi Furusawa}

Oral and Maxillofacial Surgery, Matsumoto Dental University, Shiojiri, Nagano 399-078I, Japan
Correspondence: Minoru Yamaoka Oral and Maxillofacial Surgery, Matsumoto Dental University, Shiojiri, Nagano 399-078I, Japan

$\mathrm{Tel}+8 \mid 2635 \mathrm{I} 2075$

Fax +81263512076

Email yamaoka@po.mdu.ac.jp

\begin{abstract}
Although mandibular third molar has a high risk of infection extending any complications, the influence of diabetes on radiolucency and acute inflammation in pericoronitis remains unclear. The present study was to evaluate whether radiolucency below the crown is related to acute inflammation in mandibular horizontal incompletely impacted third molars and to review the records of 140 men more than 45 years with and without diabetes. The odds ratio of exhibiting acute inflammation was 3.38 (95\% CI: $1.13-10.16, \mathrm{p}<0.05)$ and that of exhibiting severe acute inflammation was 15.38 (95\% CI: 3.56-66.49, $\mathrm{p}<0.0001)$, indicating an association of acute pericoronitis in diabetes. The frequency of radiolucency below the crown and below the root in diabetics was similar to that in nondiabetics. However, the odds ratio of exhibiting both radiolucency below the crown and acute inflammation under the diabetic condition was 4.85 (95\% CI: $1.60-14.73, \mathrm{p}<0.01)$, whereas that of diabetics showing both radiolucency below the root and acute inflammation was 0.46 (95\% CI: 0.06-3.74, p = 0.74). Radiolucency below the crown and acute inflammation were associated with diabetes, but that below root and acute inflammation were not associated with diabetes, indicating that the region below the crown carries susceptibility to acute pericoronitis, whereas the periodontium shows a protective effect against acute pericoronitis.
\end{abstract}

Keywords: radiolucency, acute inflammation, mandible, third molar, diabetes, periodontium

\section{Introduction}

A close relationship between diabetes and periodontitis has been highlighted by a number of studies. Periodontitis is an infection affecting the periodontium that is twice as prevalent in diabetics compared to nondiabetics, ${ }^{1,2}$ and the prevalence of diabetes is higher in persons with periodontitis than in controls. ${ }^{2}$ The difference in periodontitis between diabetics and nondiabetics is related to a decline of the regenerative capacity, ${ }^{3-6}$ decline of reactions against alterations in the environment, ${ }^{3}$ the destruction of periodontal tissue, ${ }^{4,5,7}$ deep pockets, ${ }^{3}$ alveolar bone loss, ${ }^{3,8}$ tooth loss,,${ }^{9,10}$ visible plaque and gingival bleeding, ${ }^{11}$ an increase of the pro-inflammatory cytokines interleukin-1 $\beta$ (IL-1 $\beta$ ) and tumor necrosis factor- $\alpha(\mathrm{TNF}-\alpha),{ }^{12,13}$ and the dysregulation of normal cytokine/growth factor signaling. ${ }^{4,5,7}$ Diabetes increases apoptosis and decreases the number of bone-lining cells, osteoblasts, and periodontal ligament fibroblasts, ${ }^{14}$ and induces increased osteoclast formation and resorption as well as the inhibition of collagen production by osteoblasts, and apotosis of osteoblasts or their precursors, resulting in reduced bone formation that occurs after resorption. ${ }^{6}$ Further, periodontitis could exacerbate diabetes-induced hyperlipidemia, immune cell alterations, and impair the tissue repair capacity. ${ }^{15}$ 
However, well-balanced criticism has been targeted at the association between periodontitis and diabetics, and it remains unclear how the frequency of risk of bone resorption in diabetics is higher than nondiabetics. The difference between the two groups is not significant regarding the plaque index, age of diabetic onset, duration of diabetes, present age, insulin dosage/weight, or serum glucose, ${ }^{16}$ and diabetics show a similar extent of oral hygiene, as well as gingival and periodontal disease as measured by the percentages of surfaces or sites graded using the plaque index, gingival index, bleeding on probing, probing pocket depth, and clinical attachment loss. ${ }^{17}$

Circadian rhythm-induced variations in plasma IL-1 $\beta$ have been shown, ${ }^{18}$ and, recently, a circadian variation of crevicular IL-1 $\beta$ was identified, leading to lower levels in the morning than in the afternoon. ${ }^{19}$ Since periodontal ligament cells have an influence on alveolar bone formation, ${ }^{20}$ importantly, effective periodontal care may activate periodontal ligament cells, reducing bone resorption risk factors. Thus, there are some uncertainties regarding the bone resorption in diabetics, as bone resorption around teeth varies both within and between jaws. Therefore, even if the two opinions described above conflict with each other, the treatment of periodontitis would be the same, irrespective of whether diabetes is present or not.

On the other hand, despite the possible contribution of diabetes to acute inflammation of periodontitis, the relationship of acute periodontitis and bone resorption has not been shown to be associated with diabetes except for a case report of severe periodontitis in a diabetic patient. ${ }^{21}$ Similarly, there is a question of whether acute pericoronitis is affected by diabetes, although mandibular third molar has a high risk of infection extending complications, and case reports of severe acute inflammation resulting from pericoronitis have shown necrotizing fasciitis ${ }^{22,23}$ in which the T-cell immunoglobulin and mucin domain (TIM) family synergizes with Toll-like receptors (TLR). ${ }^{24}$ Furthermore, the diagnosis of radiolucency around the mandibular third molar was too ambiguous to exclude unequivocal bone resorption by tumor or cyst. Most radiolucencies remain incompletely understood. Effects of diabetes on radiolucency are also unknown. We hypothesized that the complicated clinical features of periodontitis result from the presence of periodontium and dental cement, which makes it difficult to identify acute inflammation in radiographic findings as an indicator of diabetics. We focused on the possibility that loss of periodontium and cement could be responsible for acute inflammation.
We attempted to elucidate whether the underlying radiolucencies below crown of the mandibular horizontal impacted third molar which represents loss of periodontium could be effective in expression of acute inflammation, and whether a substantial radiolucency below the crown of mandibular third molar could be depend on exposure to risk factor of diabetes mellitus. We wish to suggest a relationship between acute pericoronitis, which could result from chronic inflammation, and radiolucency below the crown in patients with diabetes. Advances in the understanding of bone resorption at sites where enamel is in contact with bone may offer insight into the function of the periodontium. Bone resorption and acute inflammation associated with diabetics will be discussed.

\section{Methods}

Patients were referred to the Matsumoto Dental University Hospital, Oral and Maxillofacial Surgery, for consulting or treating mandibular third molar between April, 1985 and January, 2009. Those with and without diabetes, restricted in our analysis to those more than 45 years of age, were examined at the baseline (Table 1). Patients were interviewed regarding diabetes, and some patients had blood glucose level measured at the initial examination. Diabetes was noted in 14 out of 140 men and two out of 91 women. Because the number of women with diabetes was limited, we did not analyze radiolucency and acute inflammation in the mandibular third molar of women. None of the patients had retinopathy, nephropathy, or neuropathy. Mesioangular, horizontal incompletely impacted third molars, of which crown is partly on a level of alveolar bone ridge, were monitored regarding radiolucency below the crown and below the root of the tooth to the cemento-enamel junction. Mean age \pm SD of 140 men was $55.27 \pm 8.06$; range: $45-76$ years). Fourteen (mean age \pm SD: $59.21 \pm 7.87$ years; range: $45-71$ years) of the 140 men had diabetes, and 126 men (mean \pm SD: $54.83 \pm 7.99$ years; range: $45-76$ years) were nondiabetics. No significant difference was observed between the group of men with and without diabetes $(p=0.0 .053)$. Dental radiographs from 15 teeth from 14 men with diabetes and 127 teeth from 126 men without diabetes were assessed during the initial examination. Patients were classified based on the presence/absence of: acute pericoronitis, bone resorption below the crown of the horizontal incompletely impacted third molar, and that below the root. Acute pericoronitis showed redness, swelling, tenderness on palpation, and/or purulent gingival discharge with spontaneous pain of the gingival and alveolar mucosa in the region of the mandibular third molar. 
Table I Baseline characteristics of patients with diabetes

\begin{tabular}{|c|c|c|c|c|c|c|c|c|}
\hline $\begin{array}{l}\text { Case } \\
\text { No }\end{array}$ & $\begin{array}{l}\text { Age } \\
\text { (y) }\end{array}$ & $\begin{array}{l}\text { Acute } \\
\text { pericornitis }\end{array}$ & $\begin{array}{l}\text { Severe acute } \\
\text { inflammation }\end{array}$ & $\begin{array}{l}\text { Radiolucency } \\
\text { below crown }\end{array}$ & $\begin{array}{l}\text { Radiolucency } \\
\text { below root }\end{array}$ & $\begin{array}{l}\text { Glucose } \\
\text { (mg/dl) }\end{array}$ & $\begin{array}{l}\text { Duration of } \\
\text { diabetes }(y)\end{array}$ & $\begin{array}{l}\text { Other medical } \\
\text { conditions }\end{array}$ \\
\hline I & 71 & No & No & Yes & No & 149 & & $\begin{array}{l}\text { Hypertension, } \\
\text { Hepatitis }\end{array}$ \\
\hline \multirow[t]{2}{*}{2} & 66 & No & No & No & No & & & \\
\hline & & Yes & Submandibular cellulitis & Yes & No & 183 & 20 & Hypertention \\
\hline 3 & 61 & No & Facial cellulitis & Yes & No & & 9 & Hypertension \\
\hline 4 & 57 & Yes & Periostitis & Yes & No & 96 & & \\
\hline 5 & 63 & Yes & No & Yes & No & & 10 & Hemorrhoids \\
\hline 6 & 45 & No & No & No & No & & & \\
\hline 7 & 46 & Yes & No & Yes & No & & & Hypertension \\
\hline 8 & 57 & Yes & No & Yes & No & & & Hypertension \\
\hline 9 & 53 & Yes & Periostitis & Yes & No & 146 & & $\begin{array}{l}\text { Ulcer of duodenum, } \\
\text { Cerebrum infarction }\end{array}$ \\
\hline 10 & 56 & No & No & Yes & No & & & Myocardial infarction \\
\hline II & 58 & Yes & No & Yes & No & 74 & & \\
\hline 12 & 61 & Yes & Submandibular abscess & Yes & Yes & & & Pacemaker \\
\hline 13 & 64 & Yes & No & Yes & No & 150 & 24 & \\
\hline 14 & 71 & No & No & Yes & No & & & Epicondylar fracture \\
\hline
\end{tabular}

Severe acute inflammation was from complications which extended from the acute pericoronitis in the incompletely impacted third molar. Patients with the following conditions were excluded from those selected at the initial examination: cases with periodontitis of the mandibular second molar with radiolucencies in the aspects of the mesial surface of the mesial root and the alveolar crest between the mesial and distal roots; apical radiolucency of the mandibular second or third molar; a completely impacted third molar; restoration ending below the cemento-enamel junction of the second molar; third molar stimulated mechanically by opposing teeth; or cases that were radiographically diagnosed as tumor, keratocystic odontogenic tumor, dentigerous cyst, osseous lesion in the second and/or third molars; and HIV.

\section{Radiographic assessment}

Radiographs were obtained with an X-ray machine (Morita, Tokyo or Asahi, Kyoto, Japan) and Ultra-speed dental film (Eastman Kodak, Rochester, NY, USA) at $70 \mathrm{kVp}$ and $20 \mathrm{~mA}$ in 0.32 seconds or Insight dental film (Eastman Kodak) at $70 \mathrm{kVp}$ and $7 \mathrm{~mA}$ in 0.16 seconds using the parallel technique. Radiolucency of the bone below the third molar was assessed by visual observation at $2 \times$ magnification. Measurements of presence or absence of bone resorption in radiographs were performed twice by an experienced oral surgeon. The second examination was performed at one month after the initial examination. When the measures of presence or absence of bone resorption were different between the first time and the second time, the case was excluded from the study.

\section{Statistical analysis}

Mean values \pm SD of the patients' age were calculated and analyzed statistically using Student's $t$-test among patient groups with and without diabetes. The measures were analyzed using a $2 \times 2$ Excel (Microsoft Corp., Redmond, WA, USA) statistical software. The results of comparisons between the prevalence of radiolucency below the crown or the root and acute inflammation in diabetics and nondiabetics were assessed by chi-squared tests, and the influence of potentially confounding variables was further analyzed using logistic regression analysis. Table 2 shows the categorization of these variables. Significance was accepted at the $95 \%$ confidence interval (CI) level, $\mathrm{p}<0.05$.

\section{Results}

Fifteen teeth in 14 men with diabetics and 127 teeth in 126 men without diabetes were studied. Nine teeth in diabetics and 39 teeth in nondiabetics showed acute inflammation (Table 2). Diabetics were more likely to develop acute inflammation (odds ratio [OR]: $3.38,95 \%$ CI: 1.13-10.16, $\mathrm{p}<0.05$ ) (Table 3). Moreover, cases developing severe acute inflammation of acute periostitis, the submandibular cellulitis, the facial cellulitis, or the submandibular space abscess from pericoronitis comprised five in diabetics and 
Table 2 Characteristics of patients with and without diabetes included in analysis

\begin{tabular}{|c|c|c|c|c|c|c|c|c|}
\hline \multirow[t]{2}{*}{ Age (y.) } & & \multirow[t]{2}{*}{$\begin{array}{l}\text { Size of } \\
\text { population }\end{array}$} & \multirow[t]{2}{*}{$\begin{array}{l}\text { No. of } \\
\text { teeth }\end{array}$} & \multicolumn{3}{|c|}{ Acute inflammation } & \multicolumn{2}{|c|}{$\begin{array}{l}\text { Radiolucency below } \\
\text { crown }\end{array}$} \\
\hline & & & & Present & Severe & Absent & Present & Absent \\
\hline \multirow[t]{2}{*}{$45-50$} & DM & 2 & 2 & $\mathrm{I}(50)$ & 0 & $\mathrm{I}(50)$ & $\mathrm{I}(50)$ & $\mathrm{I}(50)$ \\
\hline & Non-DM & 50 & 50 & $16(32)$ & 0 & $34(68)$ & $28(56)$ & $22(44)$ \\
\hline \multirow[t]{2}{*}{$51-60$} & DM & 5 & 5 & $4(80)$ & 2 & $\mathrm{I}(50)$ & $5(100)$ & $0(0)$ \\
\hline & Non-DM & 47 & 47 & $9(19.1)$ & 1 & $38(80.9)$ & $33(70.2)$ & |4(29.8) \\
\hline \multirow[t]{2}{*}{$6 I-70$} & DM & 5 & 6 & $4(66.7)$ & 3 & $2(33.3)$ & $5(83.3)$ & $\mathrm{I}(16.7)$ \\
\hline & Non-DM & 23 & 24 & $10(41.7)$ & 1 & $14(58.3)$ & $19(79.2)$ & $5(20.8)$ \\
\hline \multirow[t]{2}{*}{$71 \leq$} & DM & 2 & 2 & $0(0)$ & 0 & $2(100)$ & $2(100)$ & $0(0)$ \\
\hline & Non-DM & 6 & 6 & $4(66.7)$ & 2 & $2(33.3)$ & $5(83.3)$ & $\mathrm{I}(16.7)$ \\
\hline \multirow[t]{2}{*}{ Total } & DM & 14 & 15 & $9(60)$ & 5 & $6(40)$ & I3(86.7) & $2(13.3)$ \\
\hline & Non-DM & 126 & 127 & $39(30.7)$ & 4 & $88(69.3)$ & $85(66.9)$ & $42(33.1)$ \\
\hline
\end{tabular}

Abbreviation: DM, diabetes mellitus.

four in nondiabetics (Table 2). Diabetics were more likely to develop severe acute inflammation (OR: $15.38,95 \% \mathrm{CI}$ : 3.56-66.49, $\mathrm{p}<0.0001$ ) (Table 3). Thirteen teeth in men with diabetes and 85 teeth in men without diabetes showed radiolucency below the crown (Table 2). Presence of diabetes was not a significant predictor of radiolucency below the crown (OR: 3.21, 95\% CI: 0.69-14.89, p = 0.21) (Table 3). Nine out of 15 teeth in diabetics and 30 out of 127 teeth in nondiabetics showed both radiolucency below the crown and acute inflammation (Table 2; Figure 1). The odds ratio of having both radiolucency below the crown and acute inflam- mation in diabetics increased by 4.85 (95\% CI: 1.60-14.73, $\mathrm{p}<0.01$ ) (Table 3). Four out of 15 teeth in diabetics and four out of 127 teeth in nondiabetics showed both radiolucency below the crown and severe acute inflammation (Table 2). The OR of having both radiolucency below crown and severe acute inflammation in diabetics increased remarkably by 11.18 (95\% CI: 2.45-50.97, p < 0.01) (Table 3 ). One out of 15 teeth in diabetics and 35 out of 127 teeth in nondiabetics showed radiolucency below the root (Table 2). The proportion of diabetics was not a significant predictor of radiolucency below the root (OR: $0.19,95 \%$ CI: $0.02-1.48$,

Table 3 Odds ratios, 95\% Cls, and p-values from logistic regression model fitted for the dependent variable presence/absence of diabetes

\begin{tabular}{|c|c|c|c|}
\hline Independent variables & Odds ratio & $95 \% \mathrm{Cl}$ & P Value \\
\hline Acute inflammation & 3.38 & $1.13-10.16$ & $<0.05$ \\
\hline Severe acute inflammation & 15.38 & $3.56-66.49$ & $<0.0001$ \\
\hline Radiolucency below crown & 3.21 & $0.69-14.89$ & 0.21 \\
\hline $\begin{array}{l}\text { Acute inflammation and radiolucency below crown } \\
\text { (in } 15 \text { teeth in DM and I } 27 \text { teeth in Non-DM) }\end{array}$ & 4.85 & $1.60-14.73$ & $<0.01$ \\
\hline $\begin{array}{l}\text { Severe acute inflammation and radiolucency below crown } \\
\text { (in } 15 \text { teeth in DM and } 127 \text { teeth in Non-DM) }\end{array}$ & 11.18 & $2.45-50.97$ & $<0.01$ \\
\hline Radiolucency below root & 0.19 & $0.02-1.48$ & 0.15 \\
\hline $\begin{array}{l}\text { Acute inflammation and radiolucency below root } \\
\text { (in } 15 \text { teeth in DM and I } 27 \text { teeth in Non-DM) }\end{array}$ & 0.46 & $0.06-3.74$ & 0.74 \\
\hline $\begin{array}{l}\text { Sever acute inflammation and radiolucency below root } \\
\text { (in } 15 \text { teeth in DM and } 127 \text { teeth in Non-DM) }\end{array}$ & not detactable & & \\
\hline $\begin{array}{l}\text { Acute inflammation and radiolucency below crown } \\
\text { (in } 13 \text { teeth in DM and } 85 \text { teeth in Non-DM) }\end{array}$ & 4.13 & $1.17-14.53$ & $<0.05$ \\
\hline $\begin{array}{l}\text { Acute inflammation and radiolucency below root } \\
\text { (in one tooth in DM and } 35 \text { teeth in Non-DM) }\end{array}$ & not detactable & & \\
\hline
\end{tabular}

Abbreviations: $\mathrm{DM}$, diabetes mellitus; $\mathrm{Cl}$, confidence interval. 
Table 2 (Continued)

\begin{tabular}{|c|c|c|c|c|c|c|}
\hline \multicolumn{2}{|c|}{$\begin{array}{l}\text { Radiolucency below crown } \\
\text { with acute inflammation }\end{array}$} & \multicolumn{2}{|c|}{ Radiolucency below root } & \multicolumn{2}{|c|}{$\begin{array}{l}\text { Radiolucency below root } \\
\text { with acute inflammation }\end{array}$} & \multirow[t]{2}{*}{$\begin{array}{l}\text { Diagnosis of severe acute } \\
\text { inflammation }\end{array}$} \\
\hline Present & Severe & Present & Absent & Present & Severe & \\
\hline $\mathrm{I}(50)$ & 0 & $0(0)$ & $2(100)$ & $0(0)$ & 0 & \\
\hline $12(24)$ & 0 & $10(20)$ & $40(80)$ & $5(10)$ & 0 & \\
\hline $4(80)$ & 2 & $0(0)$ & $5(100)$ & $0(0)$ & 0 & Periostitis ( 2 cases) \\
\hline $7(14.9)$ & 1 & $16(34)$ & $31(66)$ & $5(10.9)$ & 0 & Facial cellulitis \\
\hline $4(66.7)$ & 2 & $\mathrm{I}(16.7)$ & $5(83.3)$ & $\mathrm{I}(16.7)$ & 1 & $\begin{array}{l}\text { Submandibular cellulitis, Facial cellulitis, } \\
\text { Submandibular space abscess }\end{array}$ \\
\hline $8(33.3)$ & 1 & $7(29.2)$ & I7(70.8) & $6(25)$ & 0 & Periostitis \\
\hline $0(0)$ & 0 & $0(0)$ & $2(100)$ & $0(0)$ & 0 & \\
\hline $3(50)$ & 2 & $2(33.3)$ & $4(66.7)$ & $\mathrm{I}(16.7)$ & 0 & Periostitis ( 2 cases) \\
\hline $9(60)$ & 4 & $\mathrm{I}(6.7)$ & $14(93.3)$ & $\mathrm{I}(6.7)$ & I & \\
\hline $30(23.6)$ & 4 & $35(27.6)$ & $92(72.4)$ & $17(13.4)$ & 0 & \\
\hline
\end{tabular}

$\mathrm{p}=0.15)$ (Table 3$)$. One out of 15 teeth in diabetics and 17 out of 127 teeth in nondiabetics showed both radiolucency below the root and acute inflammation (Table 2; Figure 2). The proportion of diabetics was not a significant predictor of both radiolucency around root and acute inflammation (OR: 0.46, 95\% CI: 0.06-3.74, p=0.74) (Table 3). One out of 15 teeth in diabetics and neither of 127 teeth in nondiabetics showed both radiolucency below root and severe acute inflammation (Table 2). It was not determined whether diabetes was a significant predictor of severe acute inflammation and radiolucency below the root or not (Table 3 ). Diabetes was a significant predictor of both radiolucency below the crown and acute inflammation (OR: 4.13, 95\% CI: 1.17-14.53, p < 0.05) (Table 3). We confirmed similar results in 15 teeth with radiolucency below the crown in patients with diabetes. One out of one tooth in diabetics and

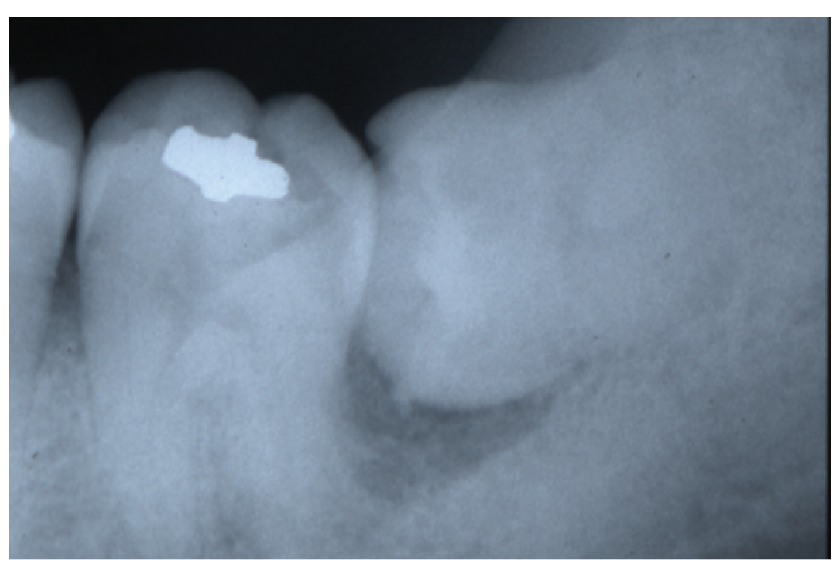

Figure I Dental radiograph reveals radiolucency below crown but not below root in a 48-year-old man with acute pericoronitis without diabetes.
17 out of 35 teeth in nondiabetics showed acute inflammation with radiolucency below the root (Table 2). It was not determined whether diabetes was a significant predictor of acute inflammation and radiolucency below the root or not (Table 3).

Moreover, these teeth were removed after anti-inflammatory treatment, and the lesions except granulation tissues were not seen after removal of teeth.

\section{Discussion}

The rate of radiolucency below the crown of horizontal incompletely impacted third molars in diabetics was not significantly greater than that in nondiabetics, and the frequency of radiolucency below the root was also nil. On the other hand, acute pericoronitis was outstandingly more prevalent in diabetics than nondiabetics, and the OR for severe

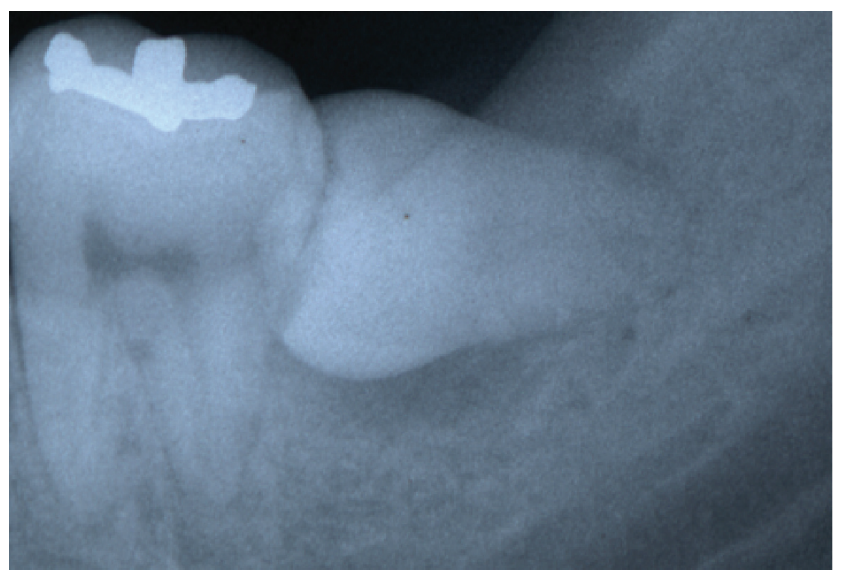

Figure 2 Dental radiograph reveals radiolucency below both crown and root in a 46-year-old man with acute pericoronitis without diabetes. 
acute inflammation markedly increased to 15.38 , indicating increased risk of acute inflammation in diabetes, and suggesting that a component of diabetes may not be radiolucency but acute inflammation. Moreover, we have shown that both radiolucency below the crown and acute inflammation in diabetics was considerably more frequent than in nondiabetics, whereas the frequency of both radiolucency below the root and acute inflammation was sparse. Radiolucency below root was unlikely to explain the magnitude of the associations observed. This indicates that acute inflammation may be associated with radiolucency below the crown. Diabetics may have risk factors, such as genetic and/or environmental factors, to relate acute inflammation in radiolucency below crown, although radiolucency below crown could not be a predictor of diabetes. Presence of periodontium may be essential for anti-inflammation, and could provide the evidence to determine the complexity of the periodontium for important immune function against acute inflammation, supporting the complexity of clinical signs and symptoms in periodontitis. These results substantiate that radiolucency under the root does not predict acute inflammation in diabetics. It is no surprise that radiolucency under the crown is at high risk for acute inflammation for diabetics, since the region around the crown had widely differing responses from the periodontium. Based on this fact, frequency of acute inflammation in pericoronitis may be noticeably more than periodontitis in diabetes. It is plausible that acute inflammation might result from diabetes due to evidence from other study. ${ }^{25,26}$ High frequency of acute inflammation in absence of periodontium may be also common in peri-implant radiolucency. Thus, our results established a basis for the effects of diabetics on pericoronitis. In parallel, the current results identify a role of periodontium not simply influenced by diabetics. These results help explain how periodontium preserve anti-inflammatory effect in men more than 45 years of age with diabetes. Bone without periodontium might be resorbed with chronic inflammation, and pericoronitis may expand to periodontitis. Indeed, chronic inflammation has been shown to lead to the progression of periodontal disease in the third molar region. ${ }^{27}$

It remains unclear whether the mechanism of acute inflammation or bone resorption in pericoronitis differs from that in periodontitis. To date, evidence regarding the effect of diabetics on periodontal disease is shown by vascular endothelial growth factor levels in periodontal soft tissues, ${ }^{28,29}$ arachidonic acid-dependent alveolar bone resorption, ${ }^{30}$ excessive production of IL- 1 and TNF- $\alpha,,^{31,32}$ regulation of TLR- 4 by TNF- $\alpha,{ }^{33}$ linkage between periodontitis and elevated serum lipids and the level of bacteremia, ${ }^{4,5}$ and a negative regulator of lipopolysaccharide/RANKL-mediated osteoclast formation. ${ }^{34}$ Moreover, regarding the association of diabetics with adipose tissue in the regulation of innate immunity, ${ }^{35,36}$ adipo $\mathrm{R}$ serves as a predominant receptor for adiponectin in the regulation of glucose and inflammation in vivo, ${ }^{37}$ although adiponectin does not appear to be influenced by periodontal treatment. ${ }^{38}$ The increased production of adiponectin is associated with the activation of 5 ' adenosine monophosphate (AMP)-activated protein kinase, resulting in increased stress tolerance. ${ }^{39}$ Requirement of the inducible nitric oxide synthase for an appropriate response to Porphyromonas gingivalis infection has been shown. ${ }^{40}$ Thus, periodontal abnormalities may be partly influenced by inflammatory changes. ${ }^{41}$ These factors may be related to not only diabetes, but also aging and radiolucency below the root. Aging significantly increases stromal/osteoblastic cell-induced osteoclastgenesis. ${ }^{42} \mathrm{Mac}-$ rophage colony-stimulating factor mediates TNF-induced inflammatory osteolysis. ${ }^{43}$ Recently, Yao and colleagues ${ }^{44}$ showed that TNF could induce c-Fos expression in osteoclast precursors at sites of inflammation in bone to promote this autocrine mechanism and thus amplify bone loss. Moreover, periodontitis could exacerbate diabetes-induced hyperlipidemia, immune cell alterations, and diminished tissue repair capacity. ${ }^{15,45}$ Inflammatory granulomas in Th1-biased mice are heavily infiltrated with osteoclasts and high local expression of interferon- $\gamma$ (IFN- $\gamma$ ), IL- $1 \alpha$, and IL-1 $\beta .{ }^{46}$ Elevated osteoprotegerin correlated with insulin resistance may reflect the proinflammatory state in type 2 diabetes. ${ }^{47}$

Since some of those factors could be associated with complex radiolucency in pericoronitis, it is difficult to obtain evidence identifying a specific cause. However, a high frequency of radiolucency below the crown associated with acute inflammation was seen in diabetics in the present study. A response to the chronic condition below the crown is differed from that below the root, and resistance against acute inflammation in the radiolucency below the crown was disabled with diabetes mellitus. More frequency of acute inflammation, which is characterized by radiolucency below the crown compared with the root, may explain why periodontium can include resistance against acute inflammation. The risk of acute pericoronitis, which occurs in the space between the crown and the bone, suggests that the periodontium has important role for immunological function. Therefore, the use of the old term "pericoronitis" as different from "periodontitis" is justifiable. Thus, 
acute inflammation seems to result from the reactivity of radiolucency modified by factors associated with diabetes. However, it is unclear whether the radiolucency below the crown in diabetes may be a predictor of the risk of the later acute inflammation. It should be investigated whether radiolucency below the crown is a preexisting and underlying risk factor predisposing to acute inflammation, or diabetes or acute inflammation is a causal factor of radiolucency below the crown.

Diabetes has been variously reported in $6.7 \%$ of a population more than 25 years of age, ${ }^{48} 2.0 \%$ to $3.2 \%$ in a Swedish population, ${ }^{49} 2.0 \%$ in men and $1.7 \%$ in women, ${ }^{50}$ $2.7 \%$ in men and $3.1 \%$ in women, ${ }^{51} 7.1 \%$ in a population more than 50 years of age, ${ }^{52}$ and $9.3 \%$ in a population more than 49 years of age. ${ }^{53}$ The lower frequency (2/91) of diabetes in women compared to men in our current study indicates a gender-related difference, suggesting differences in attitudes on health between men and women. The better oral health care-related lifestyle of women compared with men shows in this reduced rate of pericoronitis in women..$^{54,55}$

Moreover, most diabetics in this study were estimated to be type 2 diabetes mellitus from the Japanese study that a frequency of type 1 diabetes mellitus is in $5 \%-10 \%$ of diabetics. ${ }^{56}$ The results of the present study were assessed by self-report of diabetes. Limitations of our study includes the population who have no recognized diabetes and no subjective symptoms. Our findings are interpreted as representative in the community of self-reported diabetics.

\section{Conclusion}

The association between acute inflammation and radiolucency below the crown of the mandibular horizontal, incompletely impacted third molar was observed in diabetic men more than 45 years of age. However, it remains unclear when bone resorption could be detected in the chronic inflammation. And this does not always suggest the potential for early identification of men at increased risk for acute inflammation. These measurements emphasize the need for follow-up evaluation of the outcome of susceptibility to acute inflammation in many diabetics presenting with radiolucency below the crown to establish associations with radiolucency below crown and diabetes, which will be useful for risk stratification and therapeutic decision-making.

\section{Acknowledgments}

We would like to thank Ms Shiho Kobayashi for her contribution to this study. The authors report no conflicts of interest in this work.

\section{References}

1. Grossi SG. Treatment of periodontal disease and control of diabetes: an assessment of the evidence and need for future research. Ann Periodontol. 2001;6(1):138-145.

2. Soskolne WA, Klinger A. The relationship between periodontal diseases and diabetes: an overview. Ann Periodontol. 2001;6(1):91-98.

3. Hugoson A, Thorstensson H, Falk H, Kuylenstierna J. Periodontal conditions in insulin-dependent diabetics. J Clin Periodontol. 1989; 16(4):215-223.

4. Cutler CW, Machen RL, Jotwani R, Iacopino AM. Heightened gingival inflammation and attachment loss in type 2 diabetics with hyperlipidemia. J Periodontol. 1999;70(11):1313-1321.

5. Cutler CW, Shinedling EA, Nunn M, et al. Association between periodontitis and hyperlipidemia: cause or effect? J Periodontol. 1999; 70(12):1429-1434.

6. Graves DT, Liu R, Oates TW. Diabetes-enhanced inflammation and apoptosis: impact on periodontal pathosis. Periodontol 2000. 2007; $45: 128-137$.

7. Bulut U, Develioglu H, Taner IL, Berker E. Interleukin-1 beta levels in gingival crevicular fluid in type 2 diabetes mellitus and adult periodontitis. J Oral Sci. 2001;43(3):171-177.

8. Seppälä B, Ainamo J. A site-by-site follow-up study on the effect of controlled versus poorly controlled insulin-dependent diabetes mellitus. J Clin Periodontol. 1994;21(3):161-165.

9. Campus G, Salem A, Uzzau S, Baldoni E, Tonolo G. Diabetes and periodontal disease: a case-control study. J Periodontol. 2005;76(3): 418-425.

10. Lagervall M, Jansson L. Relationship between tooth loss/probing depth and systemic disorders in periodontal patients. Swed Dent J. 2007;31(1):1-9.

11. Australian Research Centre for Population Oral Health. The relationship between diabetes and oral health among Australian adults. Aust Dent J. 2008;53(1):93-96.

12. Lindemann RA, Economou JS, Rothermel H. Production of interleukin-1 and tumor necrosis factor by human peripheral monocytes activated by periodontal bacteria and extracted lipopolysaccharides. J Dent Res. 1988;67(8):1131-1135.

13. Salvi GE, Beck JD, Offenbacher S. PGE2, IL-1 beta, and TNF-alpha responses in diabetics as modifiers of periodontal disease expression. Ann Periodontol. 1998;3(1):40-50.

14. Liu R, Bal HS, Desta T, et al. Diabetes enhances periodontal bone loss through enhanced resorption and diminished bone formation. $J$ Dent Res. 2006;85(6):510-514.

15. Iacopino AM. Periodontitis and diabetes interrelationships: role of inflammation. Ann Periodontol. 2001;6(1):125-137.

16. Rosenthal IM, Abrams H, Kopczyk A. The relationship of inflammatory periodontal disease to diabetic status in insulin-dependent diabetes mellitus patients. J Clin Periodontol. 1988;15(7):425-429.

17. Khader YS, Dauod AS, El-Qaderi SS, Alkafajei A, Batayha WQ. Periodontal status of diabetics compared with nondiabetics: a metaanalysis. J Diabetes Complications. 2006;20(1):59-68.

18. Entzian P, Linnemann K, Schlaak M, Zabel P. Obstructive sleep apnea syndrome and circadian rhythms of hormones and cytokines. Am J Respir Crit Care Med. 1996;153(3):1080-1086.

19. Bergmann A, Deinzer R. Daytime variations of interleukin-1beta in gingival crevicular fluid. Eur J Oral Sci. 2008;116(1):18-22.

20. Isaka J, Ohazama A, Kobayashi M, et al. Participation of periodontal ligament cells with regeneration of alveolar bone. J Periodontol. 2001;72(3):314-323.

21. Emingil G, Darcan S, Keskinoğlu A, Kütükçüler N, Atilla G. Localized aggressive periodontitis in a patient with type 1 diabetes mellitus: a case report. J Periodontol. 2001;72(9):1265-1270.

22. Mizuno I, Mizutani H, Ueda M, Kaneda T. Temporal necrotizing infection of dental origin. J Oral Maxillofac Surg. 1993;51(1):79-81.

23. Ndukwe KC, Fatusi OA, Ugboko VI. Craniocervical necrotizing fasciitis in Ile-Ife, Nigeria. Br J Oral Maxillofac Surg. 2002;40(1):64-67. 
24. Anderson AC, Anderson DE, Bregoli L, et al. Promotion of tissue inflammation by the immune receptor Tim-3 expressed on innate immune cells. Science. 2007;318(5853):1141-1143.

25. McMahon MM, Bistrian BR. Host defenses and susceptibility to infection in patients with diabetes mellitus. Infect Dis Clin North Am 1995;9(1):1-9.

26. Joshi N, Caputo GH, Weitekamp MR, Karchmer AW. Infections in patients with diabetes mellitus. N Engl J Med. 1999;341(25):1906-1912.

27. White RP Jr, Offenbacher S, Blakey GH, et al. Chronic oral inflammation and the progression of periodontal pathology in the third molar region. J Oral Maxillofac Surg. 2006;64(6):880-885.

28. Unlü F, Güneri PG, Hekimgil M, Yeşilbek B, Boyacioğlu H. Expression of vascular endothelial growth factor in human periodontal tissues: comparison of healthy and diabetic patients. J Periodontol. 2003;74(2): 181-187.

29. Sakallioğlu EE, Aliyev E, Lütfioğlu M, Yavuz U, Açikgöz G. Vascular endothelial growth factor (VEGF) levels of gingiva and gingival crevicular fluid in diabetic and systemically healthy periodontitis patients. Clin Oral Investig. 2007;11(2):115-120.

30. Vermelin L, Baroukh B, Llorens A, Saffar JL. Effects of essential fatty acid deficiency on periodontal tissue adaptation to spontaneous tooth migration. Calcif Tissue Int. 2005;77(1):30-36.

31. Page RC. The role of inflammatory mediators in the pathogenesis of periodontal disease. J Periodontal Res. 1991;26(3 Pt 2):230-242.

32. Graves DT, Cochran D. The contribution of interleukin-1 and tumor necrosis factor to periodontal tissue destruction. J Periodontol. 2003;74(3):391-401.

33. Tamandl D, Bahrami M, Wessner B, et al. Modulation of toll-like receptor 4 expression on human monocytes by tumor necrosis factor and interleukin-6: tumor necrosis factor evokes lipopolysaccharide hyporesponsiveness, whereas interleukin-6 enhances lipopolysaccharide activity. Shock. 2003;20(3):224-229.

34. Yamaguchi N, Kukita T, Li YJ, et al. Adiponectin inhibits osteoclast formation stimulated by lipopolysaccharide from Actinobacillus actinomycetemcomitans. FEMS Immunol Med Microbiol. 2007; 49(1):28-34.

35. Creely SJ, McTernan PG, Kusminski CM, et al. Lipopolysaccharide activates an innate immune system response in human adipose tissue in obesity and type 2 diabetes. Am J Physiol Endocrinol Metab. 2007;292(3):E740-E747.

36. Vitseva OI, Tanriverdi K, Tchkonia TT, et al. Inducible Toll-like receptor and NF-kappaB regulatory pathway expression in human adipose tissue. Obesity (Silver Spring). 2008;16(5):932-937.

37. Yamauchi T, Nio Y, Maki T, et al. Targeted disruption of AdipoR1 and AdipoR2 causes abrogation of adiponectin binding and metabolic actions. Nat Med. 2007;13(3):332-339.

38. Iwamoto Y, Nishimura F, Soga Y, et al. Antimicrobial periodontal treatment decreases serum C-reactive protein, tumor necrosis factoralpha, but not adiponectin levels in patients with chronic periodontitis. J Periodontol. 2003;74(8):1231-1236.

39. Shinmura K, Tamaki K, Saito K, Nakano Y, Tobe T, Bolli R. Cardioprotective effects of short-term caloric restriction are mediated by adiponectin via activation of AMP-activated protein kinase. Circulation. 2007;116(24):2809-2817.
40. Alayan J, Ivanovski S, Gemmell E, Ford P, Hamlet S, Farah CS. Deficiency of iNOS contributes to Porphyromonas gingivalis-induced tissue damage. Oral Microbiol Immunol. 2006;21(6):360-365.

41. King GL. The role of inflammatory cytokines in diabetes and its complications. J Periodontol. 2008;79(8 Suppl):1527-1534.

42. Cao JJ, Wronski TJ, Iwaniec U, et al. Aging increases stromal/ osteoblastic cell-induced osteoclastgenesis and alters the osteoclast precursor pool in the mouse. J Bone Miner Res. 2005;20(9):1659-1668.

43. Kitaura H, Zhou P, Kim HJ, Novack DV, Ross FP, Teitelbaum SL. M-CSF mediates TNF-induced inflammatory osteolysis. J Clin Invest. 2005;115(12):3418-3427.

44. Yao Z, Xing L, Qin C, Schwarz EM, Boyce BF. Osteoclast precursor interaction with bone matrix induces osteoclast formation directly by an interleukin-1-mediated autocrine mechanism. J Biol Chem. 2008;283(15):9917-9924.

45. Graves DT, Al-Mashat H, Liu R. Evidence that diabetes mellitus aggravates periodontal diseases and modifies the response to an oral pathogen in animal models. Compend Contin Educ Dent. 2004; 25(7 Suppl 1):38-45.

46. Stashenko P, Goncalves RB, Lipkin B, Ficarelli A, Sasaki H, CamposNeto A. Th1 immune response promotes severe bone resorption caused by Porphyromonas gingivalis. Am J Pathol. 2007;170(1):203-213.

47. Yaturu S, Rains J, Jain SK. Relationship of elevated osteoprotegerin with insulin resistance, CRP, and TNF-alpha levels in men with type 2 diabetes. Cytokine. 2008;44(1):168-171.

48. Blanchard JF, Ludwig S, Wajda A, et al. Incidence and prevalence of diabetes in Manitoba, 1986-1991. Diabetes Care. 1996;19(8): 807-811.

49. Berger B, Stenström G, Chang YF, Sundkvist G. The prevalence of diabetes in a Swedish population of 280,411 inhabitants. A report from the Skaraborg Diabetes Registry. Diabetes Care. 1998;21(4):546-548.

50. Harvey JN, Craney L, Kelly D. Estimation of the prevalence of diagnosed diabetes from primary care and secondary care source data: comparison of record linkage with capture-recapture analysis. J Epidemiol Community Health. 2002;56(1):18-23.

51. Ubink-Veltmaat LJ, Bilo HJ, Groenier KH, et al. Prevalence, incidence and mortality of type 2 diabetes mellitus revisited: a prospective population-based study in The Netherlands (ZODIAC-1). Eur JEpidemiol. 2003;18(8):793-800.

52. Lipscombe LL, Hux JE. Trends in diabetes prevalence, incidence, and mortality in Ontario, Canada 1995-2005: a population-based study. Lancet. 2007;369(9563):750-756.

53. Cugati S, Wang JJ, Rochtchina E, Mitchell P. Ten-year incidence of diabetes on older Australians: the Blue Mountains Eye Study. Med J Aust. 2007;186(3):131-135.

54. Murtomaa H, Metsäniitty M. Trends in toothbrushing and utilization of dental services in Finland. Community Dent Oral Epidemiol. 1994;22(4):231-234

55. Christensen LB, Petersen PE, Krustrup U, Kjøller M. Self-reported oral hygiene practices among adults in Denmark. Community Dent Health. 2003;20(4):229-235

56. Orimo H. Gerontology, 2nd ed. Tokyo, Japan: University of Tokyo Press; 1999. p. 859.
Clinical, Cosmetic and Investigational Dentistry

\section{Publish your work in this journal}

Clinical, Cosmetic and Investigational Dentistry is an international, peer-reviewed, open access, online journal focusing on the latest clinical and experimental research in dentistry with specific emphasis on cosmetic interventions. Innovative developments in dental materials, techniques and devices that improve outcomes

\section{Dovepress}

and patient satisfaction and preference will be highlighted. The manuscript management system is completely online and includes a very quick and fair peer-review system, which is all easy to use. Visit http://www.dovepress.com/testimonials.php to read real quotes from published authors. 